\title{
Surgical algorithm and results for repair of pulmonary atresia with ventricular septal defect and major aortopulmonary collaterals
}

\author{
Richard D. Mainwaring, MD, ${ }^{\mathrm{a}}$ William L. Patrick, MD, ${ }^{\mathrm{a}}$ Stephen J. Roth, MD, MPH, ${ }^{\mathrm{b}}$ Komal Kamra, MD, \\ Lisa Wise-Faberowski, MD, ${ }^{c}$ Michal Palmon, BS, MPH, ${ }^{a}$ and Frank L. Hanley, MD ${ }^{a}$
}

\begin{abstract}
Objective: Pulmonary atresia with ventricular septal defect and major aortopulmonary collateral arteries is a complex and heterogeneous form of congenital heart disease. There is a controversy regarding the optimal treatment of pulmonary atresia with ventricular septal defect and major aortopulmonary collateral arteries. The purpose of this study was to summarize our algorithm and surgical results for pulmonary atresia with ventricular septal defect and major aortopulmonary collateral arteries.
\end{abstract}

Methods: This was a retrospective review of 307 patients undergoing primary surgical treatment of pulmonary atresia with ventricular septal defect and major aortopulmonary collateral arteries. Excluded from this analysis were patients who had undergone prior surgical treatment at another institution and patients with single ventricle and major aortopulmonary collateral arteries. There were 3 surgical pathways, including midline unifocalization $(n=241)$, creation of an aortopulmonary window $(\mathrm{n}=46)$, and other $(\mathrm{n}=20)$.

Results: For the 241 patients who underwent midline unifocalization, 204 $(85.4 \%)$ had a single-stage complete repair. There were 37 patients who underwent a midline unifocalization and central shunt, and 24 have subsequently undergone complete repair. Forty-six patients underwent an aortopulmonary window, of whom 36 have subsequently had a complete repair. There were 20 patients who had complex anatomy and underwent procedures other than described, and14 have subsequently undergone complete repair. Thus, for the patients currently eligible, $280(93.0 \%)$ have achieved complete repair. For the 204 patients who had a single-stage complete repair, the mean right ventricle to aortic pressure ratio was $0.36 \pm 0.09$. Seventy-six patients underwent a staged repair, and the mean right ventricle to aortic pressure ratio was $0.40 \pm 0.09(P<.05$ compared with single-stage repair). There were $3(1.5 \%)$ early and $8(4.0 \%)$ late deaths for the single-stage complete repair cohort versus $4(4.0 \%)$ early and $15(14.9 \%)$ late deaths for all other procedures $(P<.01)$.

Conclusions: The data demonstrate that more than $90 \%$ of patients with pulmonary atresia with ventricular septal defect and major aortopulmonary collateral arteries achieved complete repair. The overall mortality was significantly lower in the subgroup of patients who underwent single-stage complete repair. (J Thorac Cardiovasc Surg 2018;156:1194-204)

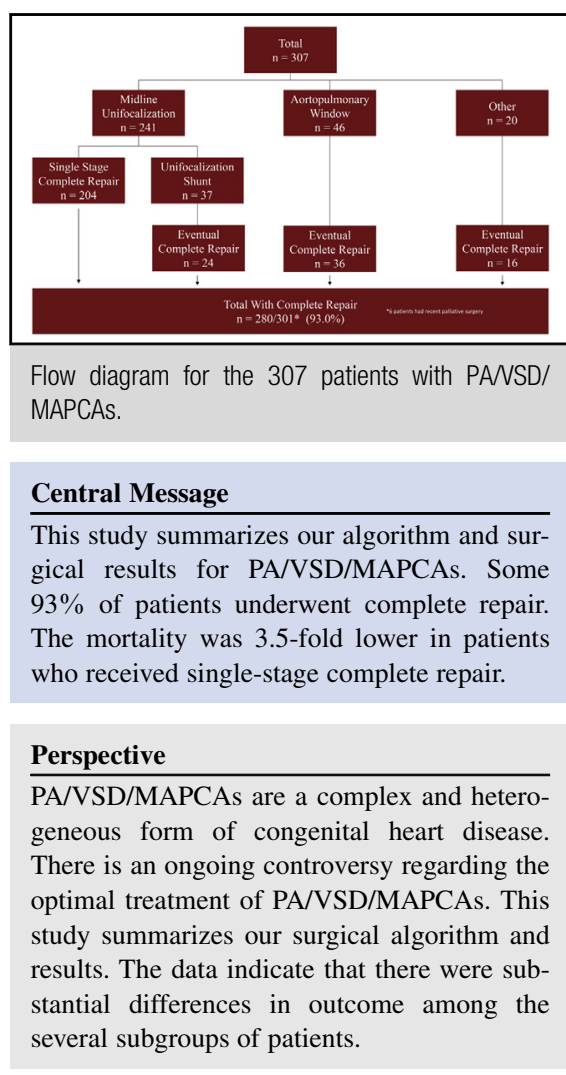

See Editorial Commentary page 1205.
From the Divisions of ${ }^{\mathrm{a}}$ Pediatric Cardiothoracic Surgery, ${ }^{\mathrm{b}}$ Pediatric Cardiology, and ${ }^{c}$ Pediatric Cardiac Anesthesia, Stanford University School of Medicine, Lucile Packard Children's Hospital Stanford, Stanford, Calif.

Certification of Human Subjects Approvals at Stanford University, Protocol ID 33924, approved on April 14, 2015.

Read at the 97th Annual Meeting of The American Association for Thoracic Surgery, Boston, Massachusetts, April 29-May 3, 2017.
Received for publication April 15, 2017; revisions received Feb 15, 2018; accepted for publication March 7, 2018; available ahead of print May 19, 2018.

Address for reprints: Richard D. Mainwaring, MD, Stanford University School of Medicine, 300 Pasteur Drive, Falk CVRC, Stanford, CA 94305 (E-mail: mainwaring@stanford.edu).

$0022-5223 / \$ 36.00$

Copyright () 2018 by The American Association for Thoracic Surgery

https://doi.org/10.1016/j.jtcvs.2018.03.153 


\section{Abbreviations and Acronyms \\ MAPCA = major aortopulmonary collateral artery \\ PA $=$ pulmonary atresia \\ VSD $=$ ventricular septal defect}

Scanning this $Q R$ code will take you to a supplemental video for the article. To view the AATS Annual Meeting Webcast, see the URL next to the webcast thumbnail.

Pulmonary atresia with ventricular septal defect and major aortopulmonary collateral arteries (PA/VSD/MAPCAs) is a relatively rare and heterogeneous form of congenital heart disease. The natural history of this congenital heart defect is poor, with 10 -year and 20 -year survivals of $50 \%$ and $20 \%$, respectively. ${ }^{1,2}$ The early treatment strategies focused on staged thoracotomy procedures and had little impact on prognosis for the group as a whole. On the basis of these results, Bull and colleagues ${ }^{1}$ advocated for the abandonment of operations that offered limited benefit to the patient but subjected them to the morbidity of these surgical procedures.

In the mid-1990s, Reddy and colleagues ${ }^{3}$ proposed the midline unifocalization approach to PA/VSD/MAPCAs. This approach entails a technically demanding surgical procedure but is extremely versatile in its application. As such, it can be used for the many diverse forms of MAPCA and pulmonary artery anatomy that may be encountered. ${ }^{4-6}$ There are numerous groups that have subsequently adopted the midline unifocalization approach and have achieved favorable results compared with the untreated natural history. ${ }^{7-10}$

Despite the relative success of the midline unifocalization approach, there is an ongoing controversy regarding the optimal treatment of PA/VSD/MAPCAs. The Melbourne group has concluded that the unifocalization of MAPCAs confers no long-term benefit, and their group has focused on efforts at "pulmonary artery rehabilitation." 11,12 This approach does not include the unifocalization MAPCAs, and they have subsequently reported their results for this approach. ${ }^{13}$ There are many other groups that have adopted the pulmonary rehabilitation approach, as evidenced by the plethora of articles that have been published on this subject in the last 10 years. ${ }^{14-20}$ It is evident that the optimal surgical treatment of PA/VSD/MAPCAs remains controversial, with the Stanford and Melbourne groups representing the 2 antithetical extremes.
Our group at Stanford has accrued the largest singlecenter experience in the world with the surgical treatment of PA/VSD/MAPCAs. The purpose of this article is to summarize the Stanford algorithm and experience with the surgical treatment of PA/VSD/MAPCAs.

\section{MATERIALS AND METHODS}

This study was approved by the Institutional Review Board at Stanford University (Protocol ID 33924). Patients included in this study had a diagnosis of PA/VSD/MAPCAs and underwent all aspects of their surgical treatment at Stanford. The time frame incorporated begins in 2001 through February 2017. A total of 307 patients met these criteria, including 149 men and 158 women. A total of 209 patients (34\%) had DiGeorge syndrome (22q11 deletion), and 13 patients ( $4 \%$ ) had Alagille syndrome. The median age at the time of operation was 4.5 months, with a range of 0.1 to 11.5 years (Figure 1, A). The median weight at the time of surgery was $5.1 \mathrm{~kg}$ (range, $2.1-41.8 \mathrm{~kg}$ ).

Specifically excluded from this analysis are 167 patients who had surgery performed at an outside institution and were subsequently referred to Stanford for reoperation, because this cumulative experience has been recently published. ${ }^{21}$ There were 50 patients who were excluded because they had intracardiac diagnoses other than PA/ VSD. ${ }^{22}$ Finally, there were 6 patients who required emergency surgical intervention for life-threatening cyanosis and were excluded from analysis. All 6 of these patients died in the short-term or midterm and underscore the futility of such emergency procedures for patients in extremus.

All patients underwent a preoperative cardiac catheterization to delineate the pulmonary artery and MAPCA anatomy. There were 211 patients who were discharged from the hospital after their neonatal cardiac catheterization and subsequently readmitted for repeat cardiac catheterization and elective unifocalization.

A total of 261 patients had predominantly single-supply MAPCAs, as defined by a MAPCA that provides the only source of blood flow to a pulmonary segment. Twenty-nine of the 261 patients had a ductus arteriosus or hemi-truncus to 1 lung and MAPCAs to the contralateral lung. These 29 patients all underwent early surgical intervention because of the presence of high pressure and flow to the lung supplied by the ductus or hemitruncus.

Twenty-one patients had clinical heart failure not amenable to medical management and therefore underwent early surgical treatment. Forty-six patients $(15 \%)$ had predominantly dual-supply MAPCAs (defined by $\geq 15$ lung segments with dual supply from both the native pulmonary artery system and the MAPCAs) and met our criteria for creation of an aortopulmonary window. These specific criteria also include hypoplastic but confluent and normally arborizing pulmonary arteries in the presence of cyanosis. $^{23}$

The patients had a mean of $4.0 \pm 1.2$ MAPCAs. This included $2.2 \pm 1.0$ MAPCAs to the right lung (range, 1-5) and 1.8 \pm 0.8 MAPCAs to the left lung (range, 1-4). These data are shown in Figure 1, B. A transthoracic pressure line was placed in all patients who underwent a complete repair, and the right ventricle to aortic peak systolic pressure ratios are the values dictated in the operative report at the conclusion of that operation before chest closure.

Results are reported as means \pm standard errors and medians and ranges where appropriate. Statistical analysis to compare groups was performed using Pearson's chi-square or Fisher exact test. For this article, "operative" refers to those deaths after the index (initial) operation for each patient, "interim" refers to those deaths that occurred after discharge from the index operation but sometime before complete repair, and "late" refers to those deaths after complete repair. Comparison of actuarial curves was performed using the log-rank (Mantel-Cox) test (SPSS Statistics version 20.0; SSPS Inc, Chicago, Ill). 


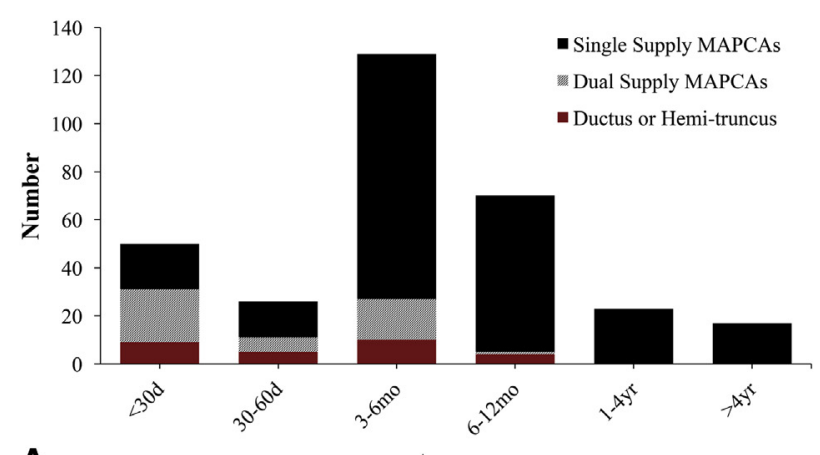

A

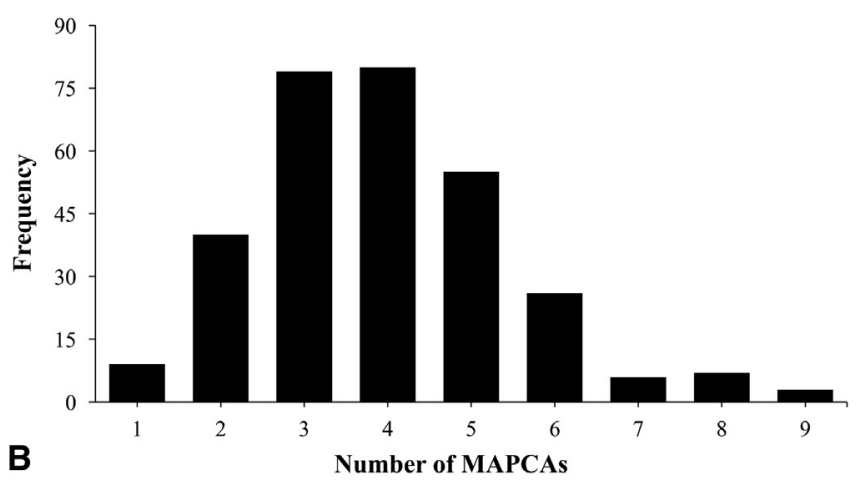

FIGURE 1. A, Histogram demonstrating the age at initial operation for the 307 patients included in this study. B, Histogram demonstrating the number of MAPCAs per patient. The mean number of MAPCAs for the entire cohort was $4.0 \pm 1.2$ MAPCAs. MAPCA, Major aortopulmonary collateral artery.

Follow-up was performed through a search of the Stanford medical records system, contacting referring physicians' offices, and searching the Social Security death registry. All deaths in this series were confirmed through these queries. Follow-up was $100 \%$ complete for all surviving patients with a 2-year window from last contact to the close of study and $96 \%$ complete with a 1-year window from last contact to the close of study.

\section{RESULTS}

For the entire cohort of 307 patients with PA/VSD/MAPCAs, 241 were deemed to be suitable candidates for a midline unifocalization approach (Video 1). A total of $204(85 \%)$ of the 241 patients underwent a single-stage complete repair (ie, $66 \%$ of the entire cohort of 307 patients had a single-stage complete repair, recognizing that 66 patients were delegated to an initial palliative procedure and thus were not eligible for a single-stage complete repair). There were 3 operative deaths $(1.5 \%)$ and 8 late deaths after single-stage complete repair. The flow diagram for the midline unifocalization patients is shown in Figure 2.

Thirty-seven patients underwent a midline unifocalization but were not candidates for simultaneous repair as assessed by an intraoperative pulmonary artery flow study. Our current criteria for the flow study uses a flow rate to the pulmonary arteries of $3 \mathrm{~L} / \mathrm{min} / \mathrm{m}^{2}$ with a maximum mean

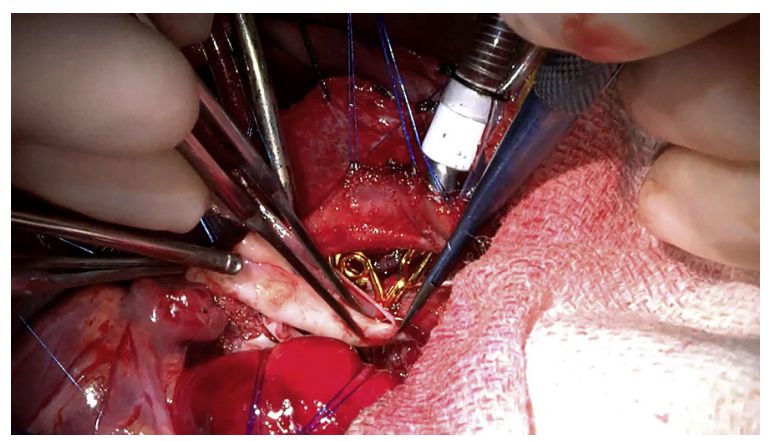

VIDEO 1. See video for more detail regarding the surgical technique for unifocalization and complete repair. Video available at: https://www.jtcvs. org/article/S0022-5223(18)30946-2/fulltext. pulmonary artery pressure of $25 \mathrm{~mm} \mathrm{Hg}$ or less. These criteria have been modified over the years to achieve a postoperative right ventricle to aortic pressure ratio less than $0.50 .^{24}$ The 37 patients who failed the flow study underwent placement of a central aortic-to-pulmonary artery shunt. There were 3 operative and 5 interim deaths. Twenty-four patients have subsequently undergone complete repair with1 late death. Three patients recently underwent their first surgery, and 2 patients have undergone multiple surgeries.

\section{SURGICAL PROCEDURES}

The 46 patients who were identified with primarily dualsupply MAPCAs underwent creation of an aortopulmonary window (Figure 2, $B$ ). There was no operative mortality after the aortopulmonary window. However, there were 4 interim and 2 late deaths. Thirty-six patients have subsequently undergone complete repair. There are 3 patients who recently had their first surgery, 1 patient has undergone multiple surgical procedures, and 2 patients are not candidates for complete repair.

Twenty patients had a surgical procedure that would fall outside the description of a midline unifocalization or aortopulmonary window (Figure 2, $C$ ). This included 15 patients with a ductus or hemi-truncus to 1 lung and MAPCAs to the other in whom the MAPCAs were small and were thought to require growth before complete unifocalization. These patients underwent a unifocalization of the MAPCAs with placement of a shunt and control of the unrestricted pressure and flow to the contralateral lung. The 5 remaining patients in this cohort had palliative shunt procedures $(\mathrm{n}=3)$ and staged thoracotomy $(\mathrm{n}=2)$. For these 20 patients, 16 have subsequently undergone complete repair. There was 1 operative death and 3 late deaths in this cohort.

The combined early and late deaths for the 204 patients who underwent single-stage complete repair was $5.4 \%$. The combined deaths for the 103 patients who underwent an initial palliative procedure was $18.9 \%$, or 3.5 times higher than the single-stage group $(P<.001)$. The actuarial 

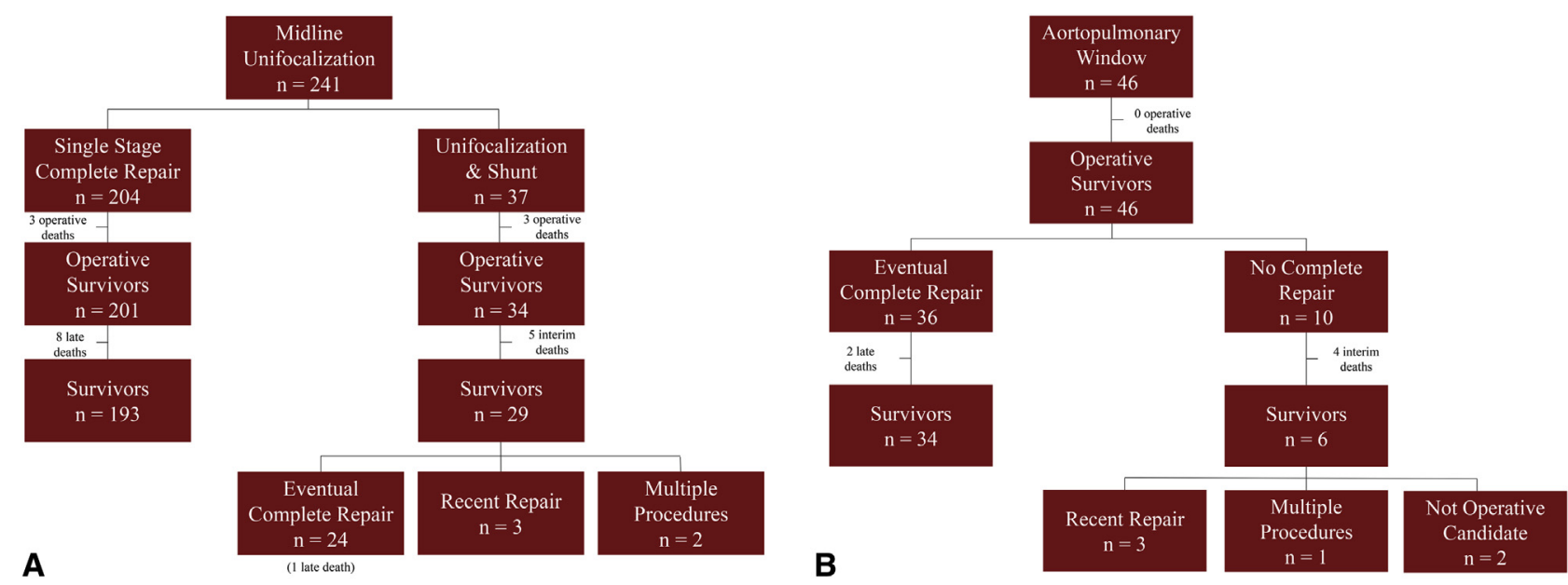

A
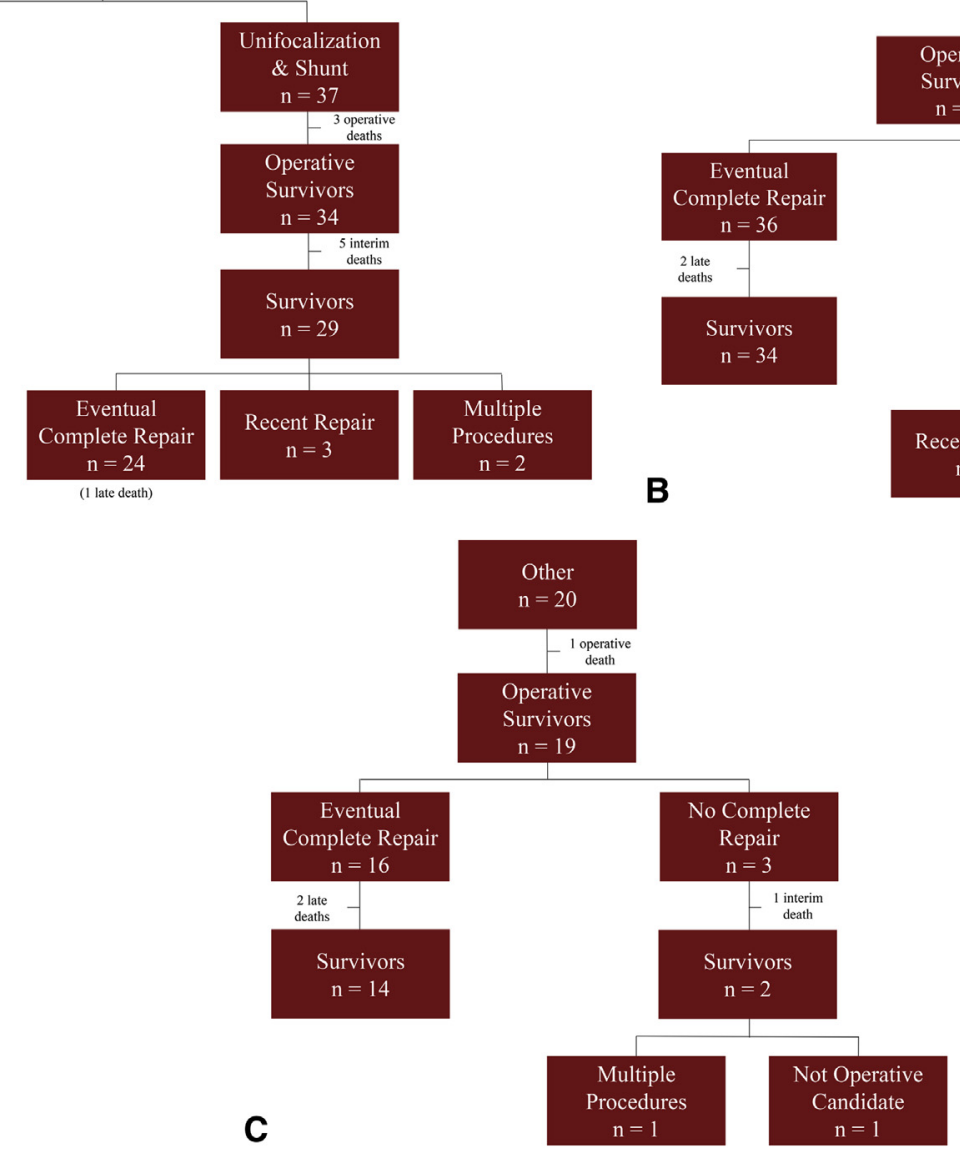

FIGURE 2. A, Flow diagram for the 241 patients with PA/VSD/MAPCAs who were candidates for a midline unifocalization. Of these 241 patients, 204 underwent single-stage complete repair and 37 underwent a unifocalization and shunt. B, Flow diagram for the 46 patients who had primarily dual-supply MAPCAs and underwent creation of an aortopulmonary window. C, Flow diagram for the 20 patients who underwent a procedure other than a midline unifocalization procedure or creation of an aortopulmonary window.

survival curves for all 307 patients are shown in Figure 3, A. The 5-year survival was $90 \%$ for the entire cohort. The actuarial survival curves for the 204 patients who underwent single-stage complete repair and for the 103 patients who underwent an initial palliative procedure are shown in Figure 3, B. The 5-year survival was $95 \%$ for patients who had a single-stage repair versus $82 \%$ in the palliative group $(P<.001)$. The mean follow-up for the 277 survivors was $5.0 \pm 0.9$ years (range, $0.1-15$ years).

A total of $280(93.0 \%)$ of 301 eligible patients achieved complete repair at some point during their surgical history (Figure 4). Six patients have recently undergone palliative surgery and to date are not yet eligible for subsequent repair. The Kaplan-Meier data are shown in Figure 5, A. The Kaplan-Meier data for single-stage complete repair versus an initial palliative procedure are shown in Figure 5, $B$. Complete repair was achieved in $100 \%$ versus $83 \%$ $(P<.001)$.
The mean right ventricle to aortic peak systolic pressure ratio for the patients receiving a single-stage complete repair was $0.36 \pm 0.09$. A histogram demonstrating the right ventricle to aortic pressure ratios for these 204 patients is shown in Figure 6, A. The mean right ventricle to aortic peak systolic pressure ratio was $0.42 \pm 0.07$ for those patients who subsequently underwent complete repair for the unifocalization/shunt, $0.40 \pm 0.06$ for the aortopulmonary window group, and $0.37 \pm 0.09$ for the "other" group. The combined mean right ventricle to aortic pressure ratios for the 76 patients who underwent an initial palliative procedure and subsequently had complete repair was $0.40 \pm 0.09(P<.01$ compared with single-stage repair). The histogram of the right ventricle to aortic pressure ratios for these 76 patients is shown in Figure 6, $B$.

Potential factors that might have an influence on outcome are summarized in Table 1 . The presence of single-supply MAPCAs was associated with more favorable outcomes, 

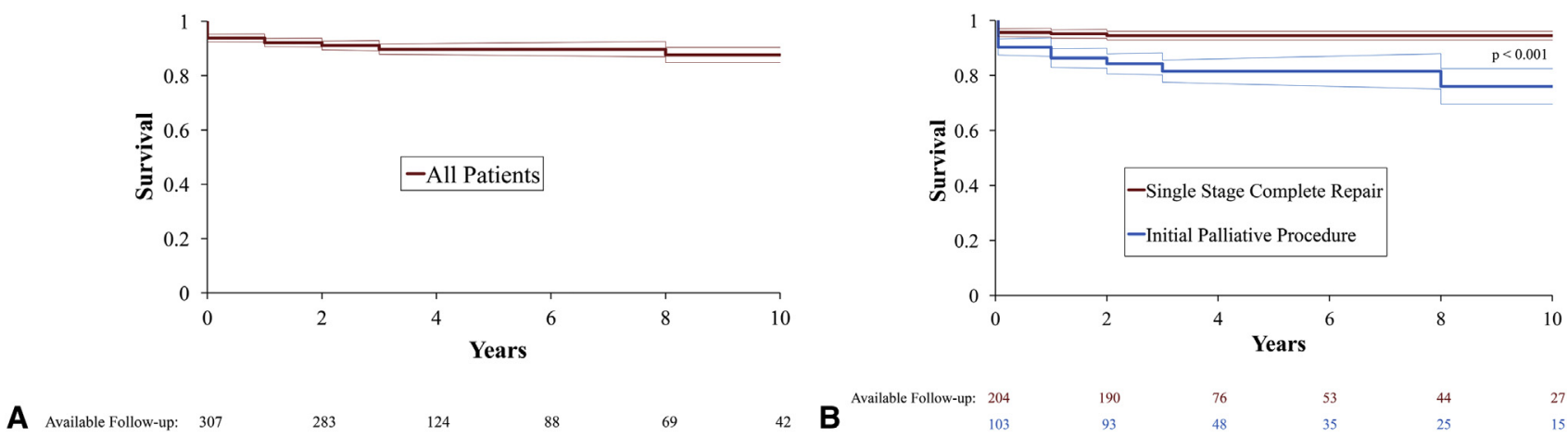

42 B

FIGURE 3. A, Actuarial survival curve for all 307 patients included in this study. B, Actuarial survival curves for the 204 patients who underwent a singlestage complete repair and for the 103 patients who initially underwent a palliative procedure. The 5 -year survival was $95 \%$ for single-stage cases versus $82 \%$ for the palliative cohort $(P<.001$ compared with single-stage $)$.

and conversely, the presence of dual-supply MAPCAs was associated with a reduced chance of achieving complete repair. The remainder of the factors had no statistically significant influence on outcomes.

\section{DISCUSSION}

This study was performed to evaluate the surgical algorithm and results achieved for patients with PA/VSD/MAPCAs who were evaluated and treated at our institution. The algorithm has 2 major pathways, those being either a midline unifocalization (for patients with single-supply MAPCAs) or creation of an aortopulmonary window (for patients with dual-supply MAPCAs). The midline unifocalization pathway was further bifurcated into those who underwent a single-stage complete repair and those who underwent unifocalization and shunt. Collectively, the 2 major pathways accounted for $93 \%$ of all patients who underwent surgical intervention at our institution.

The data demonstrate that patients who were candidates for a midline unifocalization achieved a single-stage complete repair $85 \%$ of the time. The suitability for singlestage complete repair can be assessed on the basis of the preoperative systemic oxygen saturation, which provides a good indicator of the overall pulmonary blood flow. Patients with saturations of $85 \%$ will have a Qp:Qs between 1.5 and 2.0, and thus will have a well-developed pulmonary vascular bed. These patients can almost invariably undergo a single-stage complete repair, and we no longer perform a flow study in this setting. Patients with saturations of approximately $80 \%$ will have a Qp:Qs of 1.0 ,

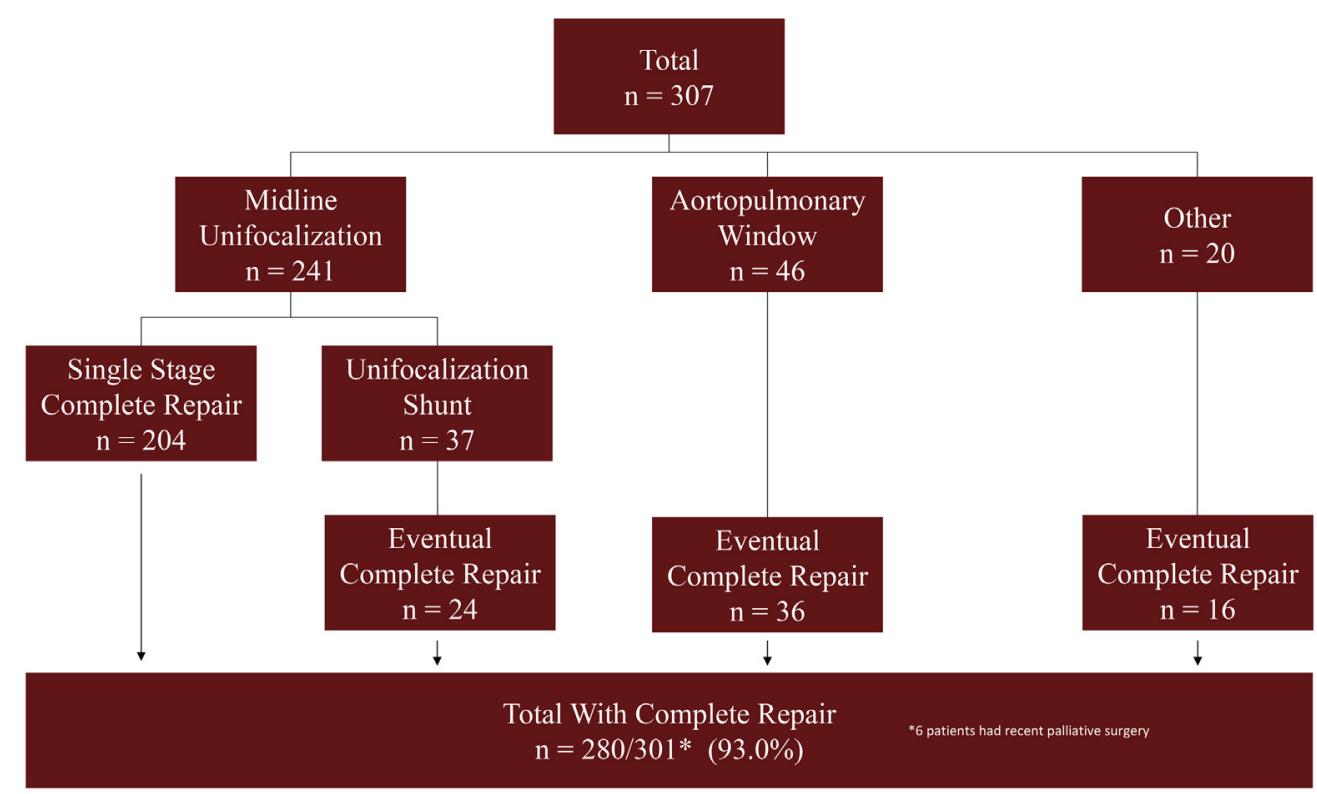

FIGURE 4. Flow diagram demonstrating the source and number of patients who achieved complete repair. A total of 280 patients ( $93 \%$ ) have achieved complete repair at some point during their surgical course. 


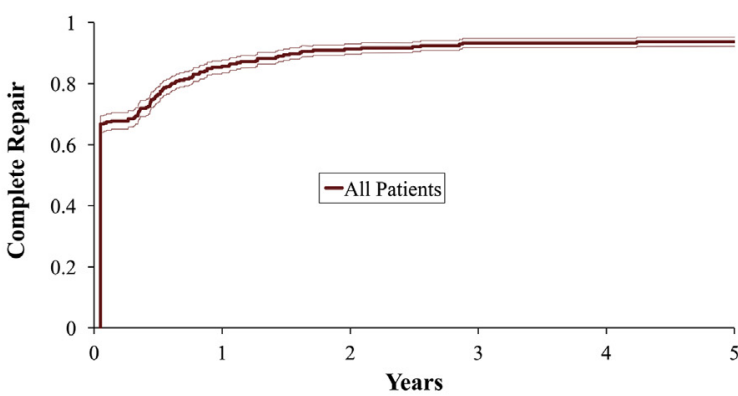

A Available Follow-up: 307 299

168

124

103

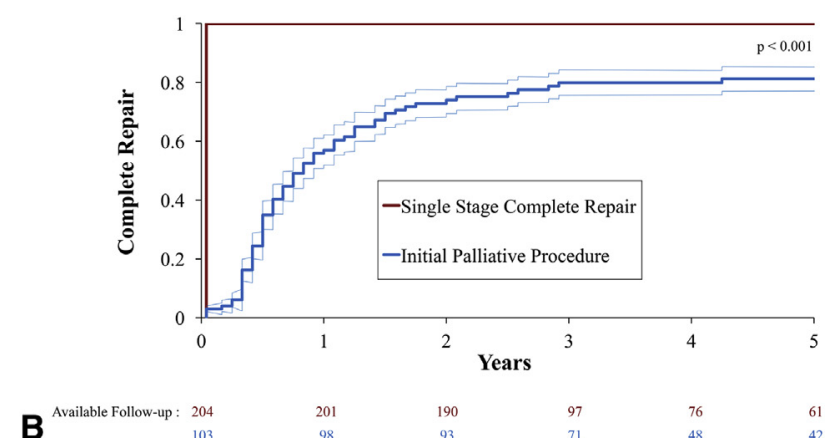

FIGURE 5. A, Kaplan-Meier curve demonstrating the ability to achieve complete repair for all 307 patients included in this study. B, Kaplan-Meier curve demonstrating the ability to achieve complete repair for the 204 patients who underwent a single-stage complete repair and for the 103 patients who initially underwent a palliative procedure. The complete repair status was $100 \%$ for single-stage complete repair versus $57 \%$ at 1 year and $83 \%$ at 5 years for the palliative cohort $(P<.001)$.

and we would perform a flow study in this circumstance to determine the suitability for single-stage complete repair. Patients with saturations of $75 \%$ or less will have a Qp:Qs substantially less than 1.0, and some may not be suitable candidates for a single-stage complete repair. Many of the patients who are not able to undergo a single-stage complete repair can subsequently achieve complete repair status. However, these patients have a higher early and late mortality and ultimately have slightly higher right ventricular to aortic pressure ratios than patients who underwent single-stage complete repair. Thus, there is a hierarchy of suitability for complete repair, with patients who have excessive pulmonary blood flow as the most favorable candidates, patients with balanced pulmonary flow as moderately ideal, and patients with limited pulmonary flow as the least ideal.

Patients who were not candidates for complete repair after unifocalization underwent placement of a central shunt. We do not perform a "fenestrated" VSD patch and do not place a right ventricle to pulmonary artery conduit in the presence of an open VSD, because we believe that pulmonary blood flow is more reliably controlled by a central shunt. Our experience has also shown that false aneurysms develop in many patients when the conduit suture lines are subjected to the systemic pressure. The patients who undergo unifocalization and shunt are reassessed 4 to 6 months after their initial surgery, and many of these patients $(80 \%)$ can ultimately achieve complete repair. Collectively, $96 \%$ of the midline unifocalization cohort eventually achieved a complete repair. This cohort accounts for the preponderance of patients in our algorithmic approach and provides a benchmark for what can be achieved in single-supply MAPCA cases.

The right ventricle to aortic peak systolic pressure ratios are shown in Figure 6, $A$ and $B$, demonstrating a comparison between patients who underwent a single-stage complete repair versus an initial palliative procedure. These data demonstrate a slight (0.36 vs 0.40$)$ but statistically significant difference. These pressure measurements are taken at the conclusion of the operative procedure and recorded in the operative note, and thus are readily retrievable for all patients undergoing a complete repair. These measurements are taken at a time when the patients are receiving lowdose dopamine, epinephrine, and milrinone, and are ventilated with $100 \%$ oxygen with 20 parts per million of nitric oxide. There are a small number of patients who have low right ventricle to aortic pressure ratios, and we would hypothesize this correlates with the observation that a small number of patients have large MAPCAs capable of supplying luxuriant amounts of pulmonary blood flow.

The other major arm of our algorithm applies to patients who have primarily dual-supply MAPCAs with hypoplastic but confluent and normally arborizing pulmonary arteries, which accounts for $15 \%$ of the entire cohort of patients with PA/VSD/MAPCAs. For this group, we perform an aortopulmonary window in the first few weeks of life to promote growth of the native and normally arborizing pulmonary artery system. ${ }^{23}$ These patients are subsequently candidates for complete repair, many without the need for unifocalization of any MAPCAs.

However, the results of this approach do not equal the results achieved in patients with single-supply MAPCAs undergoing unifocalization. Specifically, although there was no mortality associated with the aortopulmonary window procedure, the interim and late mortality in this group was 3 -fold higher than in patients undergoing single-stage complete repair. In addition, there was a lower likelihood of achieving complete repair, and for those who do, the right ventricle to aortic pressure ratios were significantly higher compared with the single-stage group.

The less favorable outcomes after aortopulmonary window are consistent with the observation that patients who begin with cyanosis are less optimal candidates than those with higher saturations.

The current study summarizes an experience with 307 patients who underwent the entirety of their surgical management at our center. As such, the focus of this study differs 
TABLE 1. Characteristics of the 307 surgical patients with pulmonary atresia/ventricular septal defect/major aortopulmonary collateral artery

\begin{tabular}{|c|c|c|c|c|c|}
\hline & Complete & Repair & $P$ value & Alive & $P$ value \\
\hline Male & $\mathrm{n}=149$ & 135 & .54 & 133 & .70 \\
\hline Female & $\mathrm{n}=158$ & 145 & & 144 & \\
\hline \multicolumn{6}{|l|}{ Age } \\
\hline$(0-60 d)$ & $\mathrm{n}=70$ & 60 & .16 & 61 & .39 \\
\hline (3-12 mo) & $\mathrm{n}=196$ & 181 & & 177 & \\
\hline$(>1 \mathrm{y})$ & $\mathrm{n}=41$ & 39 & & 39 & \\
\hline DiGeorge syndrome & $\mathrm{n}=108$ & 99 & .93 & 95 & .30 \\
\hline No DiGeorge & $\mathrm{n}=199$ & 181 & & 182 & \\
\hline Alagille syndrome & $\mathrm{n}=13$ & 10 & .10 & 10 & .11 \\
\hline No Alagille & $\mathrm{n}=294$ & 270 & & 267 & \\
\hline Primarily single-supply MAPCAs & $\mathrm{n}=232$ & 218 & $.005^{*}$ & 212 & .26 \\
\hline Primarily dual-supply MAPCAs & $\mathrm{n}=46$ & 36 & $.003^{*}$ & 40 & .42 \\
\hline Ductus or Hemi-truncus & $\mathrm{n}=29$ & 26 & .73 & 25 & .50 \\
\hline Total with absent central pulmonary arteries & $\mathrm{n}=80$ & 73 & .99 & 75 & .28 \\
\hline Single-supply MAPCAs with absent central pulmonary arteries & $\mathrm{n}=55$ & 50 & .99 & 53 & .13 \\
\hline \multicolumn{6}{|l|}{ No. of MAPCAs } \\
\hline (1 or 2$)$ & $\mathrm{n}=49$ & 41 & & 42 & .60 \\
\hline (3 or 4$)$ & $\mathrm{n}=161$ & 145 & .09 & 145 & \\
\hline (5 or 6$)$ & $\mathrm{n}=81$ & 78 & & 75 & \\
\hline$(7,8$, or 9$)$ & $\mathrm{n}=16$ & 16 & & 15 & \\
\hline
\end{tabular}

MAPCA, Major aortopulmonary collateral artery. $* P<.05$.

significantly from previous summaries of our data, which included all patients who underwent unifocalization regardless of whether they had prior surgery at an outside institution. ${ }^{21,25}$ We believe this is an important distinction to make, because it has become increasingly clear that the 2 populations are disparate. Many patients from outside institutions have undergone multiple procedures and were referred specifically because they failed to progress to complete repair.

Many of these patients had lost pulmonary blood flow to multiple segments of lung in the process. These patients typically had undergone a surgical algorithm that we would not ascribe to, further complicating the subsequent surgical management. These patients often require complex pulmonary artery reconstructions that have little semblance to unifocalization procedures and are often rehabilitative in nature. ${ }^{26}$ We believe the exclusion of these patients provides a focus on the management according to our institutional algorithm at Stanford.

Several recent publications have evaluated the influence of genetic syndromes on outcomes after surgery for PA/VSD/ MAPCAs. ${ }^{27,28}$ One third of the patients in the current study had DiGeorge syndrome, and $4 \%$ had Alagille syndrome. ${ }^{29}$ The data demonstrated that DiGeorge syndrome was not an incremental risk factor for mortality or inability to achieve complete repair. Of note, these results are different compared with our previous reports that included patients treated at Stanford and patients who underwent previous surgery at outside institutions. ${ }^{21,25}$ This disparity presumably is due to a higher-risk category (eg, airway problems) in patients referred after prior surgery at other institutions. The number of patients with Alagille syndrome was insufficient to demonstrate a difference in outcomes.

There has been much speculation regarding the influence of pulmonary artery anatomy on the outcome of surgery for PA/VSD/MAPCAs. ${ }^{7-9}$ In our series, 55 of 232 patients $(23 \%)$ with primarily single-supply MAPCAs had absent central pulmonary arteries. In addition, 25 of the 29 patients with ductus/hemi-truncus had absent central pulmonary arteries. Thus, 80 of 307 patients in this series had absent central pulmonary arteries. However, the absence of central pulmonary arteries was associated with the same outcome measures compared with patients who had central pulmonary arteries, as we had previously reported. ${ }^{4}$ Many patients with absent central pulmonary arteries will have large MAPCAs, which provide luxuriant pulmonary blood flow, thus placing these patients in the most favorable physiologic category. The absence of native pulmonary artery tissue is readily made up for by the substantial MAPCA size that greatly facilitates reconstruction of the pulmonary vascular bed.

The anatomy of MAPCAs is heterogeneous, with great variability in size, number, origin, and quality. The most 

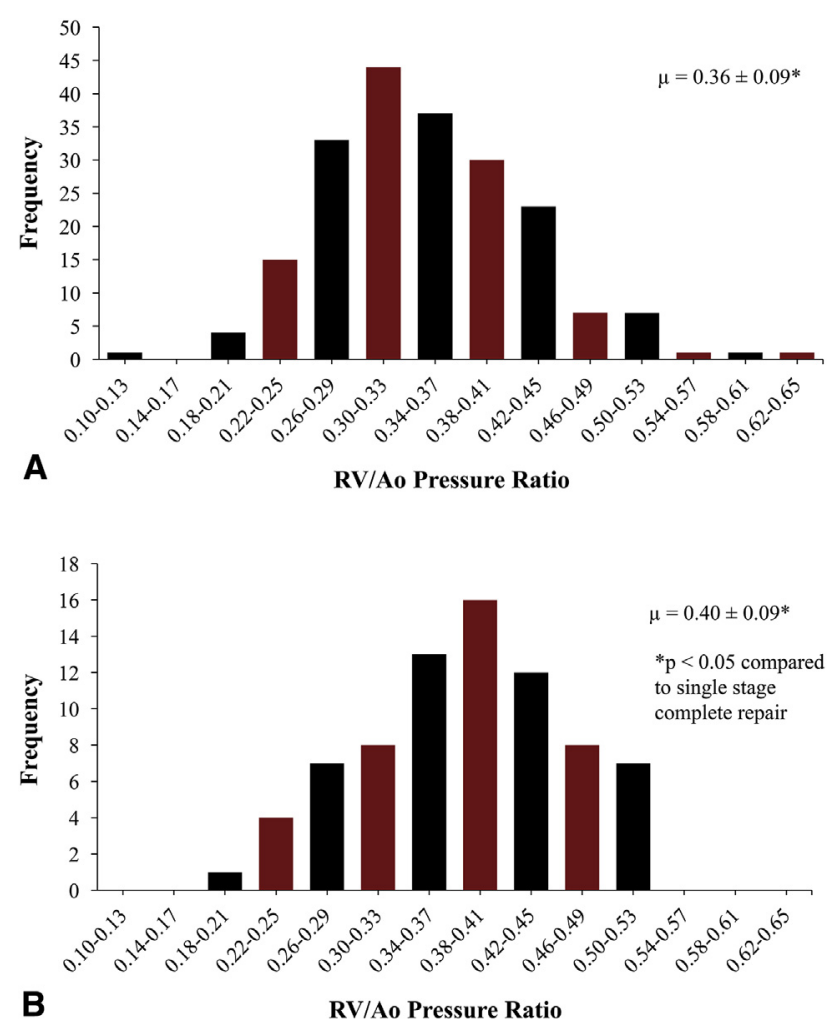

FIGURE 6. A, Histogram demonstrating the distribution of right ventricle to aortic peak systolic pressure ratios in the 204 patients who underwent a single-stage complete repair. The data shown are intraoperative data at the completion of the surgical procedure. The mean pressure ratio was $0.36 \pm 0.09$. B, Histogram demonstrating the distribution of right ventricle to aortic peak systolic pressure ratios in the 76 patients who initially underwent palliative procedures and subsequently had a complete repair. The data shown are intraoperative data at the completion of the surgical procedure. The mean pressure ratio was $0.40 \pm 0.09$. $R V$, Right ventricle; Ao, aortic.

common origin of MAPCAs is off the anterior surface of the descending aorta. However, two thirds of patients will have a retro-esophageal MAPCA, which originates from the lateral side of the aorta. ${ }^{30}$ Retro-esophageal MAPCAs are frequently posterior to the airway and have midsegment stenoses, and therefore require a different surgical approach compared with MAPCAs originating from the anterior aorta. MAPCAs also may originate from the brachiocephalic vessels, and these are generally smaller in caliber, supply a smaller number of lung segments, and are typically of poorer overall quality. Our philosophy is to unifocalize all single-supply MAPCAs that supply more than 1 lung segment, and MAPCAs that have significant stenoses may require patch augmentation before unifocalization. There is a wide variability in the quality of MAPCAs, and to date, no studies have attempted to characterize the relationship between quality of MAPCAs and outcomes.

After discharge from the hospital, patients undergo a surveillance program that includes quarterly echocardiograms and oxygen saturation measurements, a lung perfusion study at 6 months, and a cardiac catheterization at 1 year postoperatively. Any significant abnormalities in noninvasive studies should prompt an earlier diagnostic catheterization and may also provide an opportunity to perform catheter-based interventions. Specifically, discrete stenoses of the central branch pulmonary arteries or unifocalized pulmonary arterial bed may be amenable to balloon dilation. In addition, conduit stenosis can be treated with balloon dilation or stenting to increase the longevity of the conduit. These catheter-based interventions provide a valuable adjunct to the surgical armamentarium. However, we would strongly discourage placement of stents in the central or peripheral branch pulmonary arteries, because stents inevitably develop neointimal fibrous tissue and become stenotic at the site of the stent.

Our preference is to surgically address abnormalities of the distal unifocalized bed (ie, beyond the hilum), principally using pulmonary artery homograft patches to augment areas of stenosis. We have also used ostioplasty techniques in selective circumstances. ${ }^{26}$ The timing of this surgical intervention is based on the pulmonary artery pressure. Moderate or severe cases may mandate early reintervention to relieve right ventricular hypertension. In contrast, mild cases may be followed, with the timing of surgical intervention determined by conduit longevity. In a recent study, we reported that $18 \%$ of patients who underwent a midline unifocalization have subsequently required unifocalization revision. The risk factors for requiring unifocalization revision included single-stage complete repair versus unifocalization/shunt, higher right ventricle to aortic pressure ratios at the time of repair, and absence of central pulmonary arteries. ${ }^{31}$

The results in this article can be juxtaposed with those achieved using the pulmonary artery rehabilitation approach. ${ }^{11-20}$ Many groups have adopted this approach to $\mathrm{PA} / \mathrm{VSD} / \mathrm{MAPCAs}$ in recent years. The data indicate that $50 \%$ to $80 \%$ of patients achieve complete VSD closure with right ventricle to pulmonary artery pressures in the range of 0.60 to 0.70 . These pressure ratios would suggest that pulmonary blood flow is markedly restricted. In our view, the most likely explanation for this physiologic result is the exclusion of single-supply MAPCAs to areas of lung that have no overlap with the native pulmonary artery distribution. If these single-supply MAPCAs are not incorporated, the segments of lung supplied by these MAPCAs will not receive antegrade pulmonary blood flow, and the overall cross-sectional area of the pulmonary vascular bed is reduced. It is also conceivable that some patients enrolled in pulmonary artery rehabilitation programs have excessive pulmonary artery flow and pressure for an extended period of time, resulting in the development of pulmonary vascular obstructive disease. Although we fully endorse the aortopulmonary window approach for the $15 \%$ of patients with dual-supply MAPCAs, we would put forth a 
word of caution in applying this concept to patients with significant single-supply MAPCAs.

\section{CONCLUSIONS}

Our group has pioneered the midline unifocalization approach to PA/VSD/MAPCAs. The data demonstrate that more than $90 \%$ of patients with PA/VSD/MAPCAs achieved complete repair, with a mean right ventricle to pulmonary artery pressure ratio of 0.36 . The data also highlight that there were important disparities in outcomes between discrete subsets of patients. Specifically, patients who had a single-stage complete repair had the most favorable outcomes, whereas patients who underwent a palliative procedure had less favorable outcomes. These results provide a validation of the surgical algorithm and approach that have been developed for patients with PA/VSD/MAPCAs.

\section{Webcast}

You can watch a Webcast of this AATS meeting presentation by going to: https://aats.blob.core.windows.net/media/17AM/ 2017-05-03/RM306/05-03-17_Room306_0814_Hanley.mp4.

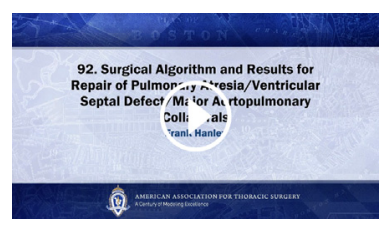

\section{Conflict of Interest Statement}

Authors have nothing to disclose with regard to commercial support.

\section{References}

1. Bull K, Somerville J, Spiegelhalter D. Presentation and attrition in complex pulmonary atresia. J Am Coll Cardiol. 1995;25:491-9.

2. Leonard H, Derrick G, O'Sullivan J, Wren C. Natural and unnatural history of pulmonary atresia. Heart. 2000;84:499-504.

3. Reddy VM, Liddicoat JR, Hanley FL. Midline1-stage unifocalization and repair of pulmonary atresia with ventricular septal defect and major aortopulmonary collaterals. J Thorac Cardiovasc Surg. 1995;109:832-45.

4. Carrillo SA, Mainwaring RD, Patrick WL, Bauser-Heaton H, Peng L, Reddy VM, et al. Surgical repair of pulmonary atresia/ventricular septal defect/major aortopulmonary collaterals with absent intra- pericardial pulmonary arteries. Ann Thorac Surg. 2015;100:606-14.

5. Mainwaring RD, Reddy VM, Hanley FL. Surgical reconstruction of pulmonary stenosis with ventricular septal defect and major aortopulmonary collaterals. Ann Thorac Surg. 2013;95:1417-21.

6. Watanabe N, Mainwaring RD, Reddy VM, Palmon M, Hanley FL. Early complete repair of pulmonary atresia with ventricular septal defect and major aortopulmonary collaterals. Ann Thorac Surg. 2014;97:909-15.

7. Griselli M, McGuirk SP, Winslaw DS, Stumper O, de Giovanni JV, Miller P, et al. The influence of pulmonary artery morphology on the results of operations for major aortopulmonary collateral arteries and complex congenital heart defects. J Thorac Cardiovasc Surg. 2004;127:251-8.

8. Carotti A, Albanese SB, Filleppelli S, Rava L, Guccione P, Pongiglione G, et al. Determinants of outcome after surgical treatment of pulmonary atresia with ventricular septal defect and major aortopulmonary collateral arteries. J Thorac Cardiovasc Surg. 2010;140:1092-103.

9. Davies B, Mussa S, Davies P, Stickley J, Jones TJ, Barron DJ, et al. Unifocalization of major aortopulmonary collateral arteries in pulmonary atresia with ventricular septal defect is essential to achieve excellent outcomes irrespective of native pulmonary artery morphology. J Thorac Cardiovasc Surg. 2009;138:1269-75.

10. Amark KM, Karamlou T, O’Connell A, MacDonald C, Freedom RM, Yoo SJ, et al. Independent risk factors associated with mortality, reintervention, and achievement of complete repair in children with pulmonary atresia with ventricular septal defect. J Am Coll Cardiol. 2006;47:1448-56.

11. d'Udekem Y, Alphonso N, Norgaard MA, Cochrane AD, Grigg LE, Wilkinson JL, et al. Pulmonary atresia with ventricular septal defect and major aortopulmonary collateral arteries: unifocalization brings no long-term benefits. J Thorac Cardiovasc Surg. 2005;130:1496-502.

12. Brizard CP, Liava'a M, d'Udekem Y. Pulmonary atresia, VSD and Mapcas: results without unifocalization. Semin Thorac Cardiovasc Surg Pediatr Card Surg Ann. 2009;12:139-44

13. Liava'a M, Brizard CP, Konstantinov IE, Robertson T, Cheung MM, Weintraub R, et al. Pulmonary atresia, ventricular septal defect, and major aortopulmonary collaterals: neonatal pulmonary artery rehabilitation without unifocalization. Ann Thorac Surg. 2012;93:185-92.

14. Kim H, Sung SC, Choi KH, Lee HD, Ban GH, Chang YH. A central shunt to rehabilitate diminutive pulmonary arteries in patients with pulmonary atresia with ventricular septal defect. J Thorac Cardiovasc Surg. 2014;149:515-20.

15. Mumtaz MA, Rosenthal G, Qureshi A, Prieto T, Preminger T, Lorber R, et al. Melbourne shunt promotes growth of diminutive central pulmonary arteries in patients with pulmonary atresia, ventricular septal defect, and systemic-topulmonary collateral arteries. Ann Thorac Surg. 2008;85:2079-84.

16. Hibino N, He D, Yuan F, Yu JH, Jonas R. Growth of diminutive central pulmonary arteries after right ventricle to pulmonary artery homograft implantation. Ann Thorac Surg. 2014;97:2129-33.

17. Chen Q, Ma K, Hua Z, Zhang H, Wang X, Hu X, et al. Multistage pulmonary artery rehabilitation in patients with pulmonary atresia, ventricular septal defect and hypoplastic pulmonary artery. Eur J Cardiothorac Surg. 2016;50:160-6.

18. Zhang Y, Hua Z, Yang K, Zhang H, Yan J, Wang X, et al. Outcomes of the rehabilitative procedure for patients with pulmonary atresia, ventricular septal defect and hypoplastic pulmonary arteries beyond the infant period. Eur J Cardiothoracic Surg. 2014;46:297-303.

19. Dragulescu A, Kammache I, Fouilloux V, Amedro P, Metras D, Kreitmann B, et al. Long-term results of pulmonary artery rehabilitation in patients with pulmonary atresia, ventricular septal defect, pulmonary artery hypoplasia, and major aortopulmonary collaterals. J Thorac Cardiovasc Surg. 2011;142:1374-80.

20. Song Sw, Park HK, Park YH, Cho BK. Pulmonary atresia with ventricular septal defects and major aortopulmonary collateral arteries. Circ J. 2009;73:516-22.

21. Bauser-Heaton H, Borquez A, Han B, Ladd M, Asija R, Downey L, et al. Programmatic approach to management of tetralogy of Fallot with major aortopulmonary collateral arteries: a 15 year experience with 458 patients. Circ Cardiovasc Interv. 2017;10:e004952.

22. Patrick WL, Mainwaring RD, Reinhartz O, Punn R, Tacy TA, Hanley FL. Major aortopulmonary collateral arteries in patients with anatomy other than pulmonary atresia with ventricular septal defect. Ann Thorac Surg. 2017;104:907-16.

23. Mainwaring RD, Reddy VM, Perry SB, Peng L, Hanley FL. Late outcomes in patients undergoing aortopulmonary window for pulmonary atresia/stenosis and major aortopulmonary collaterals. Ann Thorac Surg. 2012;94:842-8.

24. Mainwaring RD, Reddy VM, Peng L, Kuan C, Palmon M, Hanley FL. Hemodynamic assessment after complete repair of pulmonary atresia/major aortopulmonary collaterals. Ann Thorac Surg. 2013;95:1397-402.

25. Malhotra SP, Hanley FL. Surgical management of pulmonary atresia with ventricular septal defect and major aortopulmonary collaterals: a protocol-based approach. Semin Thorac Cardiovasc Surg Pediatr Card Surg Ann. 2009;12:145-51.

26. Mainwaring RD, Ibrahimiye AN, Hanley FL. Surgical techniques for reconstruction of peripheral pulmonary artery stenosis and other complex peripheral reconstructions. Ann Thorac Surg. 2016;102:e181-3.

27. Carotti A, Digilio MC, Piacentini G, Saffirio C, DiDonato RM, Marino B. Cardiac defects and results of cardiac surgery in 22q11.2 deletion syndrome. Dev Disabil Res Rev. 2008;14:35-42.

28. Formigari R, Michielon G, Digilio MC, Piacentini G, Carotti A, Giardini A, et al. Genetic syndromes and congenital heart defects: how is surgical management affected? Eur J Cardiothorac Surg. 2009;35:606-14.

29. Mainwaring RD, Sheikh AY, Reddy VM, Punn R, Hanley FL. Surgical results in patients with pulmonary atresia/major aortopulmonary collaterals and Alagille syndrome. Eur J Cardiothorac Surg. 2012;42:235-41.

30. Mainwaring RD, Patrick WL, Carrillo SA, Muralidaran A, Ibrahimiye AN, Hanley FL. Prevalence and anatomy of retro-esophageal major aortopulmonary collateral arteries. Ann Thorac Surg. 2016;102:877-83. 
31. Mainwaring RD, Patrick WL, Ma M, McElhinney DB, Hanley FL. An analysis of patients requiring unifocalization revision following midline unifocalization for pulmonary atresia with ventricular septal defect and major aortopulmonary collateral arteries. Eur J Cardiothorac Surg. February 13, 2018 [Epub ahead of print].

Key Words: congenital heart disease, pulmonary artery, pulmonary valve

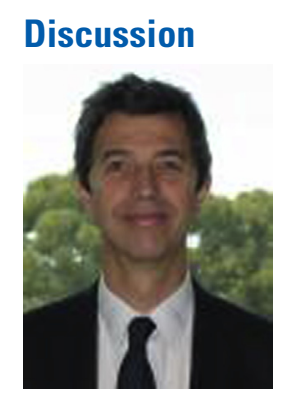

Dr Christian P. R. Brizard (Parkville, Australia). Congratulations for this remarkable work and continuity of work. I received the article well in advance. It was well written and very clear. I think it is a new iteration of earlier publications from your team aimed at educating our community in the algorithm used for decision-making in your institution. It is illustrated by your most recent and up-to-date results.

In your previous publications and including the most recent, you have successfully conveyed the message that the rationale behind your strategy was to achieve the lowest possible pulmonary artery pressure at follow-up. In the "Results" section, early and late deaths, absolute numbers, and actual probabilities are provided, but as for the hemodynamics data, the only result available to the reader is the intraoperative right ventricle to aortic pressure gradient. So my first question is about that gradient. Is it measured intraoperatively after bypass but when the chest is open?

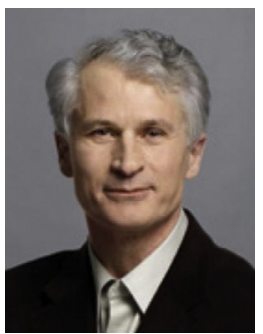

Dr Frank L. Hanley (Stanford, Calif). Yes, it is measured intraoperatively while the chest is open, but we leave a right ventricular (RV) pressure catheter placed through the right atrium, through the tricuspid valve in the left ventricle, and essentially the day before they leave the intensive care unit it gets pulled out. Typically, it decreases by approximately $5 \%$ to $10 \%$ as the inflammatory response and the elevated pulmonary vascular resistance calm down. By the time we pull the line out, it is usually $5 \%$ to $10 \%$ lower. Now, that's all very early postoperatively. We then follow the patients long term with echocardiography and lung perfusion scans looking at the RV septum and if there is a small tricuspid valve jet to evaluate the RV pressure, and we follow them that way over the long term.

Dr Brizard. To carry on, again, in your previous publications your recommendation for follow-up is a catheter study at 12 months. My second question is about this catheterization at 1 year. How many of these patients presented today have had this catheter study and what were the results?

Dr Hanley. The majority of these patients come from long distances, probably only $5 \%$ come from within our normal catchment area, and we have had difficulty getting outside referral sources to do that catheterization at 1 year or to get patients who are doing extremely well and look very well on their echocardiograms to come a couple of thousand miles just to get a catheterization. So the number of catheterizations we actually get at a year has been moderately disappointing.

So what we have tried to do to get the long-term follow-up is wait until the patients come back to us for their conduit changes. And if I can just show my next slide here, we have published on this. This was an article put together by Dr Mainwaring in 2013, so at this point we had 10-year experience with approximately 200 patients in this cohort, and these were 80 patients who came back for a conduit change, so we have definitive RV pressures in these patients. So this is 80 patients who came back for RV conduit change who had a full repair.

And just to hit the bottom point here, the RV systolic pressure at conduit change was 34 , absolute values $(\mathrm{mm} \mathrm{Hg})$, which was 2 lower than the average in these 80 patients at their initial operation, and this is at 4.5 years later. Again, these patients had their initial repair at 3, 4, or 5 months and now they are 5 or 6 years old, so there has been a massive amount of growth, and this would imply to us that these vessels actually grow quite nicely over time.

Dr Brizard. Having read your articles on the topic for many years, it appears that you have used different materials to enlarge unifocalizations. Now you constantly use a pulmonary homograft wall. Would you be able to grade the long-term performance of these various materials?

Dr Hanley. I don't recall ever using anything but pulmonary artery homografts.

Dr Brizard. You used autologous pericardium.

Dr Hanley. Some of our surgeons who may have been in our group who may have done 1 or 2 of these operations over the years may have used other material. I personally have done $95 \%$ of these operations, if not more, and I have never used anything but pulmonary artery homograft for the distal pulmonary artery reconstruction.

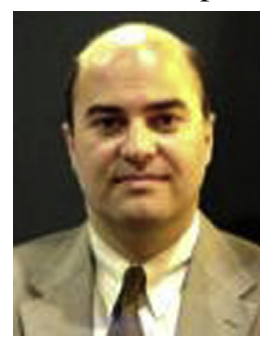

Dr Emile Bacha (New York, NY). Frank, outstanding. A quick question. When you do your complete repair, how do you decide about using a transannular patch, a conduit, and what conduit?

Dr Hanley. Everybody gets a conduit when they get their final repair. No one gets a conduit before the repair. I just do a shunt and keep their RV virgin, no ventriculotomy. And I use aortic homograft for all of these patients at the first go around, because you never know whose pressure may drift up a little bit. Pulmonary homografts at higher pressures are more likely to get aneurysmal or dilate. I don't use Contegra or the old Hancock conduits (both Medtronic, Minneapolis, Minn); they are too bulky in very young infants. So aortic 
homografts in all patients. Now, at the second time around at the conduit change, if they have shown to be very well, I may use a pulmonary artery homograft.

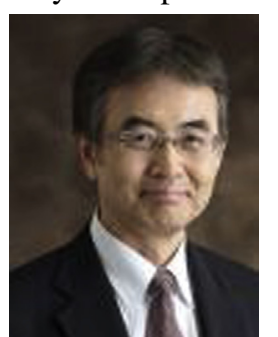

Dr Hiroshi Date (Kyoto, Japan). Have any of these patients after their repair incurred any sort of interventional catheterization, dilatation, stenting, and so on?

Dr Hanley. Absolutely. I didn't put the article up here, but Doff McElhinney has worked on an article with interventions. It's a complex issue, because the threshold for intervention has to be defined. We will intervene if there is any discrepancy in the homogeneity of flow into the pulmonary arteries even if the RV pressure has not been affected. So if a left upper lobe vessel gets stenotic, and this happens, and it doesn't affect the RV pressure and it is still very low, we will wait, and at the conduit change I will address that surgically. We do aggressively treat peripheral stenoses when they come up in the catheter laboratory with balloon dilation only, never stenting; a stent just creates a terrible problem later, and at the conduit change we can get to any of these stenoses if we have to. So ballooning is fine, stenting never. Often, if it's a nonhemodynamic lesion, we will wait until the time of the conduit change to sort of do a little rehabilitation.

Overall, approximately $20 \%$ of patients, and this is going to be in a publication coming out shortly on intervention in these groups, receive further intervention in the periphery beyond the conduit itself. So rehabilitation and careful follow-up are critically important. 